\section{SOI: 1.1/TAS DOI: 10.15863/TAS International Scientific Journal Theoretical \& Applied Science}

p-ISSN: 2308-4944 (print) e-ISSN: 2409-0085 (online)

Year: $2018 \quad$ Issue: 03 Volume: 59

Published: $30.03 .2018 \quad$ http://T-Science.org
Vasil Mihaylov

$\mathrm{PhD}$ Candidate

Department of Economics, Faculty of Economics South-West University "Neofit Rilski” - Blagoevgrad Bulgaria v_mihaylov@mail.bg

Mihail Mihaylov $\mathrm{PhD}$, Associate Professor Higher School of Security and Economics - Plovdiv Bulgaria m.mihaylov@cea.bg

SECTION 31. Economic research, finance, innovation, risk management.

\title{
IMPLEMENTATION OF THE NATIONAL TARGETS OF BULGARIA RELATED TO "EUROPE 2020" STRATEGY AND THE DEVELOPMENT OF KNOWLEDGE-BASED ECONOMY
}

\begin{abstract}
The present study focuses on the implementation of the targets of "Europe 2020" strategy in Bulgaria such as the share of early school leavers, the share of 30-34 year-olds with tertiary education and the share of all individuals with tertiary education, $R \& D$ investments, the level of employment and reducing the number of people at risk of poverty or social exclusion and covers the period 2010 - 2016. The study includes results and conclusions from research part of a dissertation related to the problems of reproduction of human capital and the future development of a knowledge-based economy in Bulgaria. The aim of the study is to analyze the progress of the implementation for 4 of the targets of the National Reforms Program in Bulgaria according to "Europe 2020" strategy which correspond to the requirements of the knowledge-based economy such as education, $R \& D$, employment and reducing the poverty levels so that more people can gain access to knowledge, adequate healthcare and culture and by that to enhance the labour productivity and the competitiveness of the economy.

Key words: knowledge, knowledge-based, economy, education, $R \& D$, employment, poverty, Bulgaria, EU

Language: English

Citation: Mihaylov V, Mihaylov M (2018) IMPLEMENTATION OF THE NATIONAL TARGETS OF BULGARIA RELATED TO “EUROPE 2020" STRATEGY AND THE DEVELOPMENT OF KNOWLEDGEBASED ECONOMY. ISJ Theoretical \& Applied Science, 03 (59): 188-191.

Soi: http://s-o-i.org/1.1/TAS-03-59-32 Doi: crossef https://dx.doi.org/10.15863/TAS.2018.03.59.32
\end{abstract}

\section{Introduction}

Growing competition, demographic problems, scarcity of resources and global focus on development of knowledge-based economies in the first and the second decade of the 21st century required the European Union to take on a new path of development outlined in "Europe 2020" strategy. It was adopted after the global financial crisis of 2008 and aimed at addressing economic and social weaknesses in each member state and promoting the important roles of education and knowledge for economic growth. The implementation of the main priorities in this ten-year strategy, according to its authors, was expected to create conditions for smart, sustainable and inclusive growth in each member state and in the European Union as a whole. Bulgaria as one of the 28 member state countries of the EU has developed its National Reform Program (updated in 2017), which corresponds to the "Europe 2020" criteria, but sets realistic levels of implementation of these criteria for the country.

The present study focuses on the implementation of the targets of "Europe 2020" strategy such as the share of early school leavers, the share of 30-34 year-olds with tertiary education and the share of all individuals with tertiary education in Bulgaria, R\&D investments, the level of employment and reducing the number of people at risk of poverty or social exclusion. The study includes results and conclusions from research part of a dissertation related to the problems of reproduction of human capital and the future development of a knowledgebased economy in Bulgaria. The aim of the study is to analyze the progress of the implementation for 4 of the targets of the National Reforms Program in Bulgaria according to "Europe 2020" strategy which correspond to requirements for the knowledge-based economy such as education, R\&D, employment and reducing the poverty levels so that more people can gain access to knowledge, adequate healthcare and culture. Statistical and analytical methods are applied for the aim of the study which covers the period 2010 - 2016.

Analysis

"Europe 2020" strategy identifies three priorities - 1/ Smart growth: building a knowledge- 


\begin{tabular}{|c|c|c|c|c|c|c|}
\hline Impact Factor: & $\begin{array}{l}\text { ISRA (India) } \\
\text { ISI (Dubai, UAE } \\
\text { GIF (Australia) } \\
\text { JIF }\end{array}$ & $\begin{array}{r}=1.344 \\
=0.829 \\
=0.564 \\
=1.500\end{array}$ & $\begin{array}{l}\text { SIS (USA) } \\
\text { PИНЦ (Russia) } \\
\text { ESJI (KZ) } \\
\text { SJIF (Morocco) }\end{array}$ & $\begin{array}{l}=0.912 \\
=0.207 \\
=4.102 \\
=2.031\end{array}$ & $\begin{array}{l}\text { ICV (Poland) } \\
\text { PIF (India) } \\
\text { IBI (India) }\end{array}$ & $\begin{array}{l}=6.630 \\
=1.940 \\
=4.260\end{array}$ \\
\hline
\end{tabular}

based economy and innovation; 2/ Sustainable growth: Promoting a greener and more competitive, resource efficient economy; 3/ Inclusive growth: Stimulating an economy with high levels of employment leading to social and territorial cohesion. For measuring the progress in achieving the objectives of the strategy, five main targets for the European Union are set: 1) Employment for $75 \%$ of the population aged 20-64; 2) R\&D investments of $3 \%$ of GDP; 3) Achieving the "20/20/20" climate/energy targets (including an additional $30 \%$ reduction if the conditions are appropriate); 4) Under $10 \%$ relative share of early school leavers and at least $40 \%$ relative share of 30-34 year-olds with tertiary education; 5) Reducing the number of people at risk of poverty by 20 million people. Bulgaria's national targets for implementing the strategy are set out in the National Reform Program of the Republic of Bulgaria (updated 2017). According to it, the national target for employment following the "Europe 2020" strategy requires employment of the country's population (20-64) of $76 \%$. The national target for investments in R\&D is $1.5 \%$ of GDP. The national target for relative share of early school leavers is $11 \%$ and at least $36 \%$ relative share of 30 34 year-olds with tertiary education, and the target for reducing the number of people at risk of poverty to be reduced - by 260 thousand people in Bulgaria. In the present study the four targets (out of five) are analyzed and their progress is measured.

\section{Results}

The results from the analysis of the implementation of the first target relate to employment show that in 2016 the employment rate in Bulgaria was $67.7 \%$ - Diagram 1.

Diagram 1. Employment rate in Bulgaria and EU (2010 - 2016) - \%

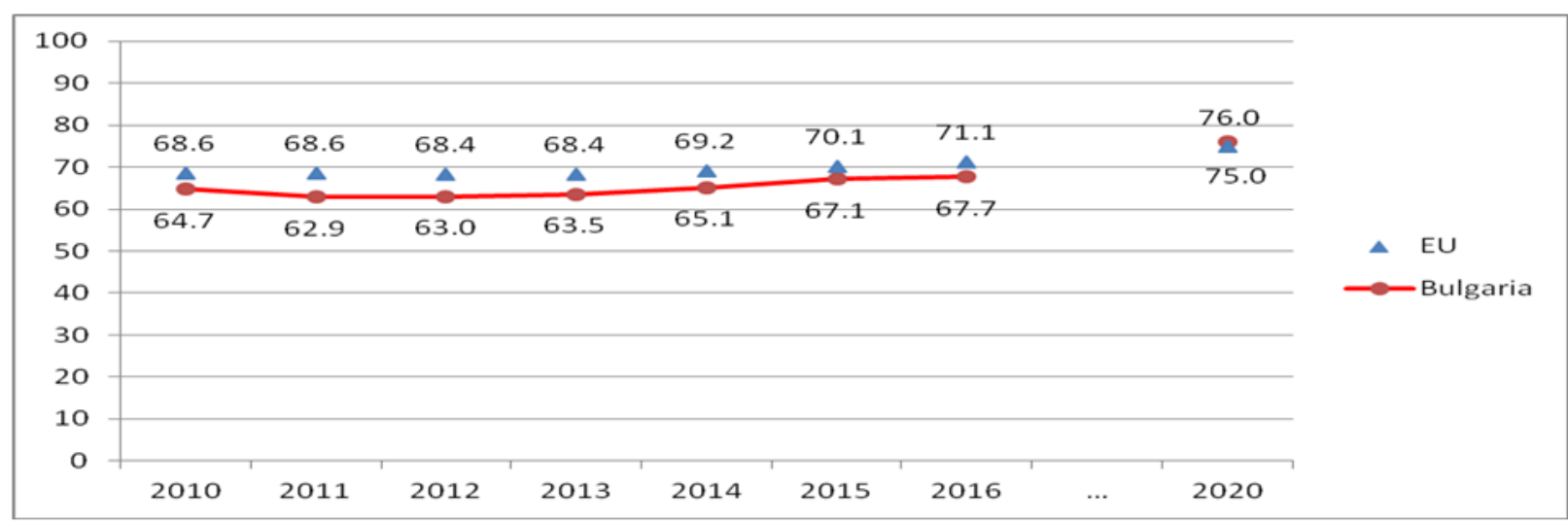

Source: National Statistical Institute - Sofia, Bulgaria

As seen on the diagram employment rates in Bulgaria and EU are very similar, but the rate for Bulgaria in 2016 is just $67.7 \%$ while the national target for 2020 is $76.0 \%$. The difference is $8.3 \%$ that should be minimized for just 4 years period. It is very likely that Bulgaria will not meet the requirements of "Europe 2020" referring to this indicator.

The second target related to the investments in R\&D show that Bulgaria the R\&D expenditure (\% of GDP) for 2016 was $0.76 \%$ - Diagram 2.

Diagram 2. R\&D expenditure in Bulgaria and EU (2010 - 2016) - \% of GDP

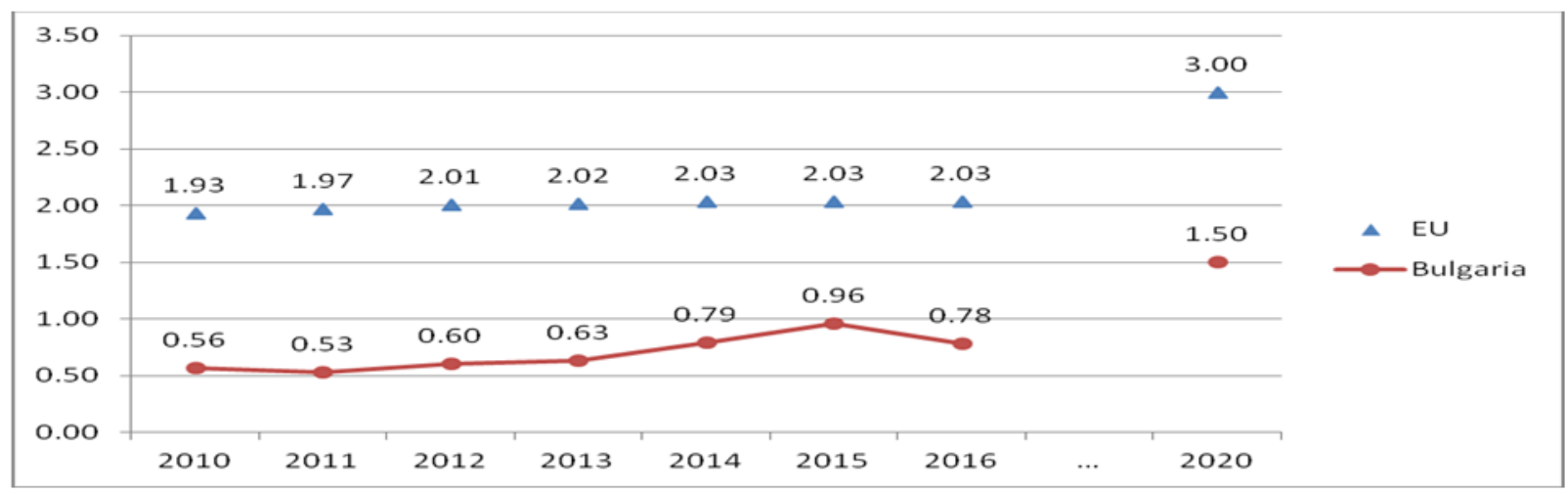

Source: National Statistical Institute - Sofia, Bulgaria 


\begin{tabular}{|c|c|c|c|c|c|c|}
\hline Impact Factor: & $\begin{array}{l}\text { ISRA (India) } \\
\text { ISI (Dubai, UAE } \\
\text { GIF (Australia) } \\
\text { JIF }\end{array}$ & $\begin{array}{r}=1.344 \\
=0.829 \\
=0.564 \\
=1.500\end{array}$ & $\begin{array}{l}\text { SIS (USA) } \\
\text { PИНЦ (Russia) } \\
\text { ESJI (KZ) } \\
\text { SJIF (Morocco) }\end{array}$ & $\begin{array}{l}=0.912 \\
=0.207 \\
=4.102 \\
=2.031\end{array}$ & $\begin{array}{l}\text { ICV (Poland) } \\
\text { PIF (India) } \\
\text { IBI (India) }\end{array}$ & $\begin{array}{l}=6.630 \\
=1.940 \\
=4.260\end{array}$ \\
\hline
\end{tabular}

The expenditure on R\&D in Bulgaria decreased from $2015(0.96 \%)$ to 2016 by $0.18 \%$. The target in 2020 is $1.50 \%$. The desired level of this indicator may not be possible to be achieved by 2020 . But for the EU may also not be possible to achieve $3 \%$ expenditure because of the 2016 level of the indicator - at $2.03 \%$. The project-oriented funding concerning "Horizon 2020" for example needs to be more simplified and by that to ensure the free and fast access of the interested scientific institutions.
The results for the third target for relative share of early school leavers is $11 \%$ and at least $36 \%$ relative share of 30-34 year-olds with tertiary education show that the percentage of early school leavers are raising instead of decreasing and the required level of this indicator in Bulgaria is far from its desired level in 2020 - it was $13.8 \%$ in $2016-$ Diagram 3.

\section{Diagram 3. Share of early school leavers in Bulgaria (2010 - 2016) - \%}

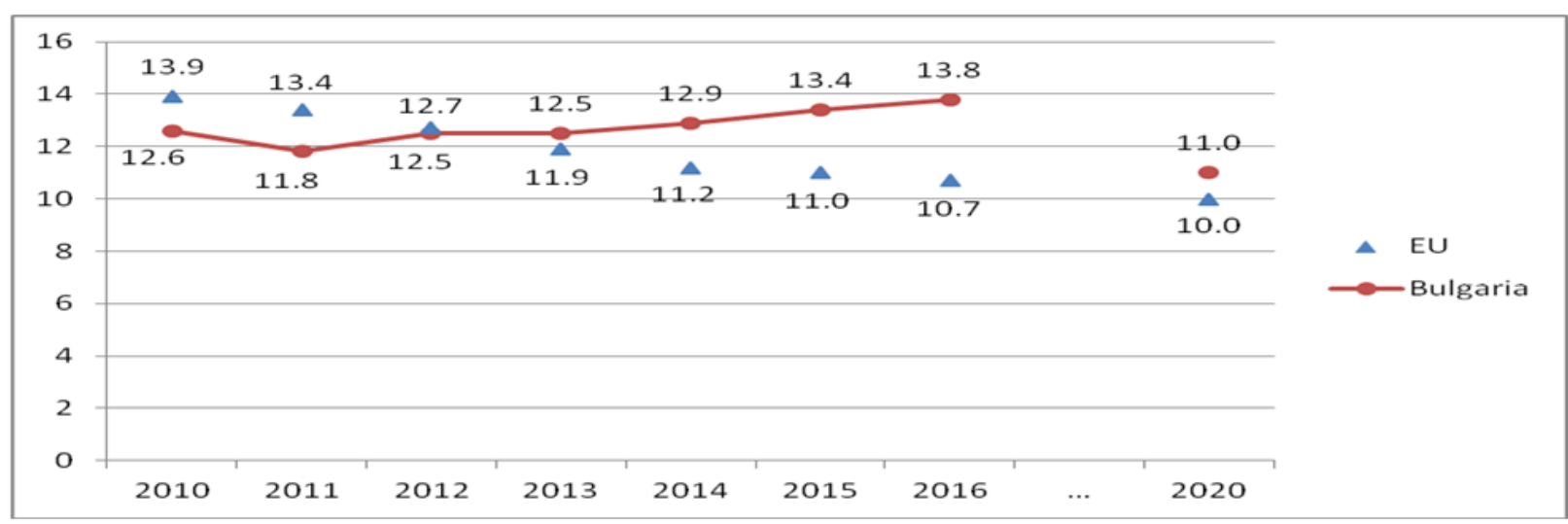

Source: National Statistical Institute - Sofia, Bulgaria

As seen on the diagram above the share of early school leavers in Bulgaria for the period raised to $13.8 \%$ in 2016. Some of the main reasons for that tendency are poverty, economic migration to
Western countries like Germany, UK, France, Sweden and low motivation to study amongst the minorities. Specific measures should be taken for tackling this negative tendency by the government.

Diagram 4. Relative share of 30-34 year-olds with tertiary education - \%

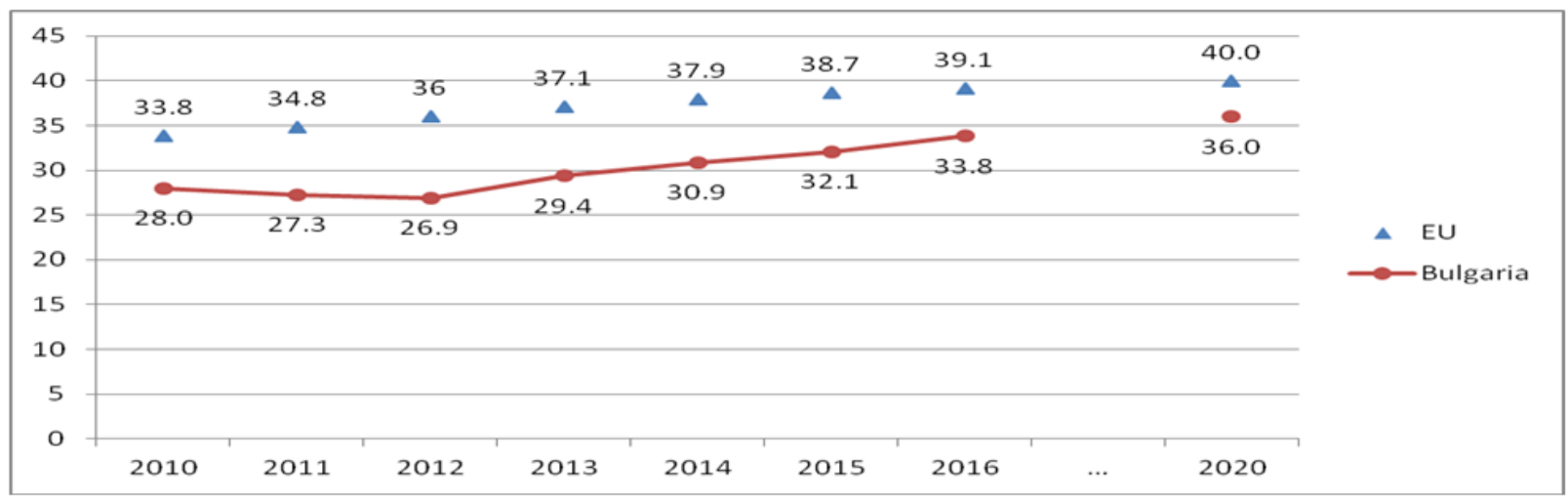

Source: National Statistical Institute - Sofia, Bulgaria

According to the diagram the second part of the third target is possible to be achieved by 2020. The share of 30-34 year-olds with tertiary education in Bulgaria in 2016 was $33.8 \%$. That is just $2.2 \%$ below the desired value. The EU has nearly reached this target already in $2016-39.1 \%$. The population with higher education represents the educated people who will drive the economy to knowledge-based economy. The higher level of education an individual possesses, the higher income he will gain. 
Diagram 5. Number of people living at risk of poverty or material deprivation (combined indicator) - \%

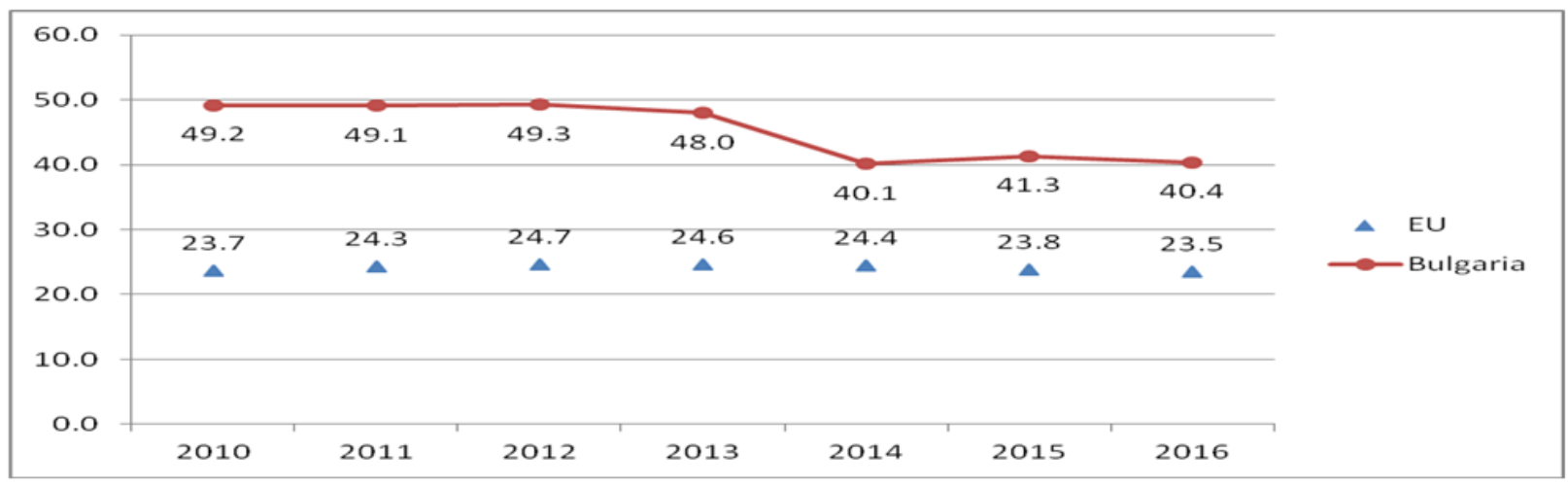

Source: National Statistical Institute - Sofia, Bulgaria

The number of people living at risk of poverty or material deprivation is decreasing for the past few years. In 2016 it dropped to $40.4 \%$ in Bulgaria which represent 2 million and 890 thousand people. This is almost $1 / 2$ from the population of Bulgaria. The European funding should be pointed in this direction. The individuals living in poverty cannot afford simple things like access to education, adequate healthcare and culture. All this interferes with the structure of human capital and its quality.

\section{Conclusions}

The results for three of the four analyzed targets (first, third and fourth) can be achieved by the EU by
2020. The process of implementation of the national targets in Bulgaria according to the "Europe 2020" strategy shows problems in the progress and probable impossibility of reaching the first, the second and partially the third target. The delayed progress on the targets can be explained by the frequent change of governments in recent years, their different priorities and the lack of sufficient administrative capacity as there are fewer and fewer well-qualified young people with the adequate qualifications working in the institutions.

\section{References:}

1. Alexandrova, Matilda. (2008). Knowledge Based Economy - Driving Forces and Some Basic Indicators. KSI Transactions on KNOWLEDGE SOCIETY.

2. Mihaylov, V. (2016), Higher Level of Education as an Opportunity for Higher Employment. Journal of Economics and Management, Faculty of Economics, SouthWest University "Neofit Rilski", Blagoevgrad, vol. 12, issue 1, 93-100

3. Mihaylov, V. (Ed.) (2016). Conditions For Research And Development In Bulgaria. The Thirteenth International Conference on Economic Sciences, Proceedings of the Conference (November 24, 2016). Vienna, OR:
«East West» Association for Advanced Studies and Higher Education GmbH, Vienna

4. (2018) Eurostat. Available: http://ec.europa.eu/eurostat/data/database

(Accessed: 10.03.2018).

5. (2018) National Statistical Institute - Sofia, Bulgaria. Available: http://www.nsi.bg/en/content/11536/indicatorseurope-2020-strategy (Accessed: 10.03.2018).

6. (2018) Strategic documents of the Council of Ministers of the Republic of Bulgaria. Available:

http://www.strategy.bg/StrategicDocuments/Vie w.aspx?Id=765 (Accessed: 10.03.2018). 


\begin{tabular}{l|lr|ll|ll} 
& ISRA (India) & $=\mathbf{1 . 3 4 4}$ & SIS (USA) & $=\mathbf{0 . 9 1 2}$ & ICV (Poland) & $=\mathbf{6 . 6 3 0}$ \\
Impact Factor: & ISI (Dubai, UAE) & $=\mathbf{0 . 8 2 9}$ & PVHL (Russia) & $=\mathbf{0 . 2 0 7}$ & PIF (India) & $=\mathbf{1 . 9 4 0}$ \\
& GIF (Australia) & $=\mathbf{0 . 5 6 4}$ & ESJI (KZ) & $=\mathbf{4 . 1 0 2}$ & IBI (India) & $=\mathbf{4 . 2 6 0}$ \\
& JIF & $=\mathbf{1 . 5 0 0}$ & SJIF (Morocco) & $\mathbf{2 . 0 3 1}$ & & \\
\hline
\end{tabular}

